\title{
Apadrinhamento Afetivo: Construindo Laços de Afeto e Proteção
}

\author{
Juliana Sonego Goulart \\ Simone dos Santos Paludo \\ Universidade Federal do Rio Grande \\ Rio Grande, RS, Brasil
}

\begin{abstract}
RESUMO
Este estudo buscou analisar a evolução do Programa Apadrinhamento Afetivo ao longo de cinco edições e identificar o seu significado para todos aqueles que estão inseridos neste. $\mathrm{O}$ estudo documental e restrospectivo identificou que foram encaminhadas 166 crianças/adolescentes e se candidataram 148 pessoas, mas apenas 59 apadrinhamentos foram efetivados. Entrevistas foram realizadas com 25 afilhados que ainda se encontravam acolhidos e um questionário foi aplicado aos seus respectivos padrinhos e madrinhas. Para os afilhados o apadrinhamento é uma possibilidade de afeto ou cuidado fora do espaço institucional enquanto para os padrinhos e as madrinhas é uma forma de ajudar outras pessoas. O Programa tem cumprido seu papel à medida que permite uma nova construção de laços de afeto e proteção.
\end{abstract}

Palavras-chave: Programa Apadrinhamento Afetivo. Acolhimento institucional. Proteção.

\section{ABSTRACT}

Affective Godfathering: Building Bonds of Affection and Protection

This study investigates the evolution of Affective Godfathering Program over five issues and identify its meaning for those who are included in this. The retrospective study identified that were sent 166 children/adolescents and 148 people have applied, but only 59 godfathering were hired. Interviews were conducted with 25 children and adolescents who were still in institutional care and a questionnaire was administered to their godfathers and godmothers. Results showed that Affective Godfathering Program is a possibility of affection or care outside the institutional care while for the godfathers and godmothers is a way to help others. The program has fulfilled its role as a new building allows bonds of affection and protection.

Keywords: Affective Godfathering Program. Institutional care. Protection.

\section{RESUMEN}

\section{Apadrinamiento Afectivo: Construyendo Lazos de Afecto y Protección}

Este estudio investiga la evolución del Programa de Apadrinamiento Afectivo en cinco ediciones e identificar su importancia para todos los que están incluidos en esta. El estudio teórico y restrospectivo identificado 166 niños que fueron referidos/los adolescentes y los 148 han solicitado, pero sólo 59 apadrinamiento fueron efectivados. Las entrevistas se llevaron a cabo con 25 ahijados que fueron recibidos y todavía se administró un cuestionario a sus padrinos. Para los ahijados el apadrinamiento es una posibilidad de afecto o atención fuera del espacio institucional, mientras que para los padrinhos y madrinas es una manera de ayudar a otros. El programa ha cumplido su papel, en la menida que permite una nueva construcción de lazos del afecto y protección.

Palabras clave: Programa de Apadrinamiento Afectivo. La atención institucional. Protección. 
O acolhimento institucional de crianças e adolescentes é uma medida de proteção que, segundo o Estatuto da Criança e do Adolescente (ECA - Lei Federal 8069/1990), deve ser de caráter provisório e excepcional. Porém, antes da Lei 12.010 de 29 de julho de 2009, rubricada como nova Lei da Adoção, observava-se que esse caráter provisório nem sempre se fazia real, ocorrendo casos em que a criança ou o adolescente permanecia por vários anos na instituição de acolhimento (IPEA, 2004). Pensando numa forma de minimizar as possíveis consequências negativas que esta situação acarretaria, foi implementado, no Estado do Rio Grande do Sul, o Programa Apadrinhamento Afetivo. Este teve início no ano de 2002, por iniciativa da Organização Não-Governamental Instituto Amigos de Lucas (IAL, 2004). Seu principal objetivo é garantir às crianças e adolescentes acolhidos a possibilidade de convivência familiar e comunitária prevista no art. $4^{\circ}$, do Estatuto da Criança e Adolescente, o qual afirma que:

É dever da família, da comunidade, da sociedade em geral e do poder público assegurar, com absoluta prioridade, a efetivação dos direitos referentes à vida, à saúde, à alimentação, à educação, ao esporte, ao lazer, à profissionalização, à cultura, à dignidade, ao respeito, à liberdade e à convivência familiar e comunitária.

Nesse sentido, o Programa Apadrinhamento Afetivo visa proporcionar experiências e referências afetivas fora do contexto do acolhimento institucional. Diante da sua recente implementação, o presente estudo teve como objetivo analisar a evolução do Programa Apadrinhamento Afetivo em um município da região sul do Estado do Rio Grande do Sul e identificar o seu significado para as crianças/adolescentes e para os padrinhos e madrinhas que estão inseridas neste.

\section{A vida no acolhimento institucional}

O último levantamento nacional sobre os abrigos, realizado pelo Instituto de Pesquisa Econômica Aplicada (IPEA), constatou que existiam cerca de 20 mil crianças e adolescentes acolhidas no país (Silva, 2004). Nesse grupo 52,6\% vivia há mais de dois anos no acolhimento, sendo que o tempo de permanência variava entre dois e dez anos $(32,9 \%$ estavam nos abrigos por um período entre dois e cinco anos, $13,3 \%$, entre seis e dez anos, e 6,4\%, por mais de dez anos), tempo demasiadamente longo que poderia interferir diretamente na sociabilidade e nos vínculos afetivos (Silva e Aquino, 2005). O longo período de vivência institucional mobilizou um importante debate na sociedade civil e jurídica culminando com a Lei 12.010 (conhecida como a Nova Lei da Adoção) que altera o art.19, no $\S 2^{\circ}$ da Lei no 8.069 do Estatuto da Criança e do Adolescente, prevendo agora que a permanência em um acolhimento não deve ser superior a dois anos. Essa decisão foi pautada nas possibilidades de atender ao interesse superior da criança e do adolescente no que diz respeito ao direito à convivência familiar, seja na família de origem ou na família substituta. No entanto, até o ano de 2010 a realidade das instituições nem sempre possibilitava a viabilização desse direito devido ao desrespeito ao caráter provisório da medida.

O longo período de vivência institucional e suas implicações no desenvolvimento daqueles que ali estão vem sendo discutido amplamente na literatura psicológica (Cavalcante, Magalhães e Pontes, 2007; Moré e Sperancetta, 2010; Oliveira e Milnitsky-Sapiro, 2007; Siqueira e Dell'Áglio, 2006).

De acordo com Siqueira e Dell'Áglio (2006) as instituições fazem parte da rede de apoio de muitas famílias brasileiras, principalmente daquelas que vivenciam a situação de pobreza. Para compreender os significados desse contexto de desenvolvimento, as autoras revisaram uma série de estudos e apontaram que não existe consenso sobre o funcionamento desse local, uma vez que podem ser identificados aspectos positivos e negativos na sua função e no seu cotidiano. Contudo, é sabido que o acolhimento deve ser uma medida de proteção quando violados os direitos da criança e do adolescente. Corroborando a essa afirmação, Oliveira e Próchno (2010) relataram que o acolhimento institucional se tornou a principal alternativa para as crianças que não possuem condições de permanecer em suas casas devido às violações promovidas pela própria família de origem.

A partir do momento que as crianças e os adolescentes estão vivendo na instituição de acolhimento, suas convivências sociais se tornam distintas. A chegada à instituição pode ser vivida como uma perda ou uma rejeição do seio familiar, alterando o sentido de pertença. Além disso, muitas poderão permanecer por longos períodos na instituição, sem poder voltar para as suas famílias de origem ou ainda ter qualquer oportunidade de estar com uma família substituta (Siqueira e Dell'Áglio, 2006). Nesse cenário, os laços afetivos estabelecidos na vinculação com outras pessoas se tornam fundamentais para uma nova significação de relações com o mundo (Mota e Matos, 2008).

Alexandre e Vieira (2004) estudaram a relação de apego entre crianças institucionalizadas e verificaram que após a separação de suas famílias, as crianças/ adolescentes tentam encontrar outras figuras de apego em diferentes situações. Para os autores, o apego ficou evidenciado nas relações de afeto e 
cuidado que estabelecem com pares e com irmãos, revelado através das brincadeiras e do desejo de ter uma família. $\mathrm{Na}$ ausência de um adulto cuidador, as crianças e os adolescentes acabam por ressignificar o que vivenciaram e compartilhar seus medos e desejos com seus pares.

Outra figura que parece ser importante nesse contexto é o monitor. Vários autores sugerem que os monitores são importantes referências de adultos cuidadores, pois orientam e protegem diariamente aqueles que estão acolhidos passando a integrar a rede de apoio social e afetivo (Barros e Fiamenghi Jr, 2007; Matos e Mota, 2008; Siqueira, Betts e Dell'Aglio, 2006; Siqueira e Dell'Áglio, 2006). A relação com os adultos dentro da própria instituição pode gerar o sentimento de "estar em casa", proporcionando uma idéia de pertença e constituindo modelos identificatórios (Mota e Mattos, 2008). Os monitores/cuidadores acabam por mediar muitos comportamentos como atenção, curiosidade, cognição, linguagem e emoções, possibilitando uma vinculação afetiva forte e constante, que proporciona o desenvolvimento físico, psíquico e social saudável (Barros e Fiamenghi Jr, 2007).

Embora o acolhimento institucional cumpra o seu papel protetivo no que diz respeito ao afastamento da criança e do adolescente das situações de violação vividas, Souza, Cabral e Berti (2010) afirmam que se a brevidade da medida não for primada, acaba-se por violar o direito correspondente ao crescimento num contexto familiar e comunitário. Essa discussão remete a primazia dos direitos das crianças e adolescentes que vivem esse tipo de situação. Para Souza, Cabral e Berti (2010) é dever da família, juntamente com a comunidade, promover o devido amparo à criança e ao adolescente, pois estes têm direito a crescer e conviver com proteção e amor, desenvolvendo, assim o afeto necessário para seu amadurecimento e sua formação humana. No caso dos meninos e meninas em situação de acolhimento, esse dever que seria dos pais, passa a ser do acolhimento institucional, da sociedade e do Estado.

\section{A vida além do contexto de acolhimento institucional}

Ter adultos significativos é essencial na vida de qualquer criança e/ou adolescente, especialmente daqueles que passaram por violações promovidas por aqueles que deveriam exercer prioritariamente o cuidado. Portanto, a existência de programas nacionais, estaduais ou municipais que promovam a convivência com adultos cuidadores e externos ao contexto do acolhimento institucional é essencial.

O próprio Estatuto da Criança e do Adolescente dispõe sobre a maior participação da comunidade nas atividades internas dos acolhimentos institucionais, assim como regulamenta a integração das crianças/adolescentes em famílias substitutas quando esgotados os recursos de manutenção na família natural ou extensa (ver artigo 92 do ECA). Reiterando os dispositivos do ECA, o Plano Nacional de Promoção, Proteção e Defesa do Direito de Crianças e Adolescentes à Convivência Familiar e Comunitária (MDS e SEDH, 2006) surge com a proposta de incorporar na plenitude a proteção integral. Embora suas propostas fortaleçam o investimento na família de origem, quando esse recurso é esgotado novas possibilidades de contato comunitário e familiar são sugeridas como as famílias acolhedoras e a adoção.

O Acolhimento Familiar foi uma solução encontrada em alguns Estados para proporcionar convivência familiar e diminuir o número de consequências negativas geradas pelo demasiado tempo de institucionalização. Este programa consiste em uma família acolher a criança/adolescente que teve seu direito violado, enquanto são tomadas as devidas medidas para seu retorno à família ou encaminhado para uma família adotiva. Dentre os objetivos estariam o cuidado individualizado e fortalecimento dos vínculos comunitários dessa criança e adolescente. Porém, como discutido por Costa e Rossetti-Ferreira (2009), essa proposta envolve questões que ainda demandam aprofundamento, discussão e adequação. A primeira está relacionada a construção de vínculos e relações afetivas na família acolhedora e a segunda se refere a uma transformação na sociedade, para que o acolhimento familiar seja visto como novas significações de família, maternidade, paternidade (Costa e Rossetti-Ferreira, 2009).

O Programa Apadrinhamento Afetivo é, assim como o acolhimento familiar, uma das maneiras encontradas para que sejam garantidos os direitos de crianças e adolescentes a convivência familiar e comunitária, mesmo estando afastados de seu contexto familiar original. Embora o Programa não seja diretamente proposto pelo Plano Nacional de Promoção, Proteção e Defesa do Direito de Crianças e Adolescentes à Convivência Familiar e Comunitária (MDS e SEDH, 2006) está identificado como uma ação que deve ser estimulada no reordenamento dos serviços de acolhimento.

Para participar do Programa, os candidatos a padrinhos e madrinhas devem cumprir uma série de requisitos, a saber: ter idade mínima de 21 anos, respeitando a diferença de 16 anos entre ambos; ter disponibilidade afetiva e apresentar ambiente familiar adequado e receptivo ao apadrinhamento; participar das oficinas de sensibilização; não fazer parte do cadastro 
de adoção; não possuir demanda judicial envolvendo crianças ou adolescentes no caso de casais, deve haver concordância mútua (IAL, 2004). Critérios também são utilizados para a inclusão da criança/adolescente no programa, sendo que esta deve ter situação jurídica definida ou conhecida e possuir possibilidades remotas ou inexistentes de adoção (IAL, 2004).

O Programa envolve um processo longo que dura em média seis meses desde o momento da inscrição. Durante esse tempo, o candidato participa das oficinas temáticas mensais que abordam assuntos como a realidade da vida nos acolhimentos, a violação de direitos, o apego, os aspectos jurídicos e a responsabilidade social do padrinho/madrinha. Esses momentos são fundamentais para que o candidato tenha consciência da sua decisão e dimensione a sua participação na vida de outra pessoa. A criança e/ou o adolescente indicado para o Programa também participa de oficinas preparatórias para conhecer a proposta, compreender a diferença entre o apadrinhamento e a adoção e discutir as possibilidades de vínculo.

Segundo IAL (2004), o encontro entre os possíveis padrinhos e madrinhas com as crianças e os adolescentes acontece ao final do processo, quando a equipe de coordenação do Programa define aqueles que estão habilitados para o apadrinhamento. Nesse momento, é ofertada uma oficina de integração para que os habilitados possam conhecer os seus candidatos a afilhados e vice-versa. A escolha é feita por afinidade e empatia.

$\mathrm{O}$ apadrinhamento afetivo tem sido mencionado em alguns estudos que tratam da rede de apoio daqueles que vivem no acolhimento (Siqueira, Tubino, Schwarz e Dell'Áglio, 2009), das interações familiares com o acolhimento (Vasconcelos, Yunes e Garcia, 2009), adoção (Dias, Silva e Fonseca, 2008) e adoção tardia (Noal e Neiva-Silva, 2007). Sobre o tema foram encontradas apenas duas publicações. Padilha, Borba, Grillo, Dahmer e Paludo (2010) tratam das expectativas dos padrinhos e madrinhas habilitados ao apadrinhamento afetivo. Já Sousa e Paravidini (2011) discutiram o apadrinhamento através do método psicanalítico. Os autores analisaram o desejo de apadrinhar entrevistando madrinhas de crianças institucionalizadas e debruçaram-se sobre um caso clínico que envolvia um casal de padrinhos e uma afilhada.

Tendo em vista que essa modalidade de cuidado ainda não foi amplamente discutida pela literatura cientifica e que as suas implicações na vida dos afilhados e dos próprios padrinhos e madrinhas ainda são desconhecidas, o presente estudo visa a analisar a evolução do Programa Apadrinhamento Afetivo e identificar o seu significado para as crianças/ adolescentes e para os padrinhos e madrinhas que estão inseridas neste.

\section{MÉTODO}

Os procedimentos metodológicos desse estudo envolveram três etapas.

Primeira etapa: Estudo do tipo análise documental e retrospectivo, desenvolvido numa instituição de referência, situada em um município da região Sul do Rio Grande do Sul, responsável pela realização do Programa Apadrinhamento Afetivo. A coleta de dados nos prontuários das edições realizadas nos anos de 2002, 2003, 2007, 2008 e 2009 possibilitou a formação de um banco que continha as seguintes informações: número de candidatos por ano, número de crianças e adolescentes inscritos por ano e número apadrinhamentos efetivados. A partir do estudo documental foi possível executar as etapas posteriores.

Segunda etapa: Após identificados os apadrinhamentos efetivados e ativos, buscou-se contatar pessoalmente todas as crianças e os adolescentes que ainda estavam no acolhimento institucional e que participavam do Programa Apadrinhamento Afetivo. Um termo de autorização foi solicitado as dirigentes dos acolhimentos institucionais onde se encontravam aqueles que poderiam participar do estudo. Da mesma forma, um termo de consentimento livre e esclarecido foi solicitado a cada um dos 25 convidados. Dois não concordaram em participar do estudo. Aqueles que aceitaram foram convidados a participar de uma entrevista semi-estruturada, individual, que tinha como objetivo de identificar o perfil dos afilhados e conhecer o significado atribuído por eles/elas ao Programa. Ao final da entrevista era solicitado o nome do padrinho ou da madrinha para que a terceira etapa pudesse ser executada.

Terceira etapa: Essa etapa contou com a participação dos padrinhos e das madrinhas das 23 crianças e adolescentes entrevistadas nos acolhimentos. Um contato inicial telefônico foi realizado com cada um dos cuidadores e um encontro foi agendado. Participaram 18 adultos, sendo 15 madrinhas e três padrinhos. Todos assinaram o termo de consentimento livre e esclarecido e preencheram um questionário fechado que buscava identificar o tempo do apadrinhamento, a dinâmica da relação estabelecida, os obstáculos enfrentados e as possibilidades de futuro.

Todos os procedimentos normativos que regem as pesquisas com seres humanos foram respeitados, tendo sido o projeto desse estudo aprovado junto ao Comitê de Ética da Universidade. 


\section{RESULTADOS E DISCUSSÃO}

\section{O que os documentos revelaram?}

O estudo documental possibilitou identificar a realização de cinco edições do Programa Apadrinhamento Afetivo até o momento da coleta de dados (maio de 2010), as quais aconteceram nos anos de 2002, 2003, 2007, 2008 e 2009 (ver Figura 1).

Como pode ser identificado na Figura 1, no total foram encaminhadas 166 crianças/adolescentes e se candidataram 148 pessoas para o Programa. Essa primeira informação evidencia que há um número superior de crianças/adolescentes encaminhadas para o Programa Apadrinhamento Afetivo quando comparado ao número de candidatos a padrinhos/ madrinhas, revelando uma realidade ainda difícil para aqueles que esperam a oportunidade de receber o afeto de uma família. Embora o direito a convivência familiar e comunitária esteja garantido no art. 19 do ECA, essa condição só pode ser satisfeita se houver pessoas dispostas a exercer o cuidado dessas crianças e adolescentes. Contudo, não basta que os candidatos estejam disponíveis ou existam em quantidade suficiente para atender as crianças e adolescentes, é preciso que eles possam exercer o papel de cuidador da melhor forma possível. Para isso, todos os candidatos inscritos devem cumprir todas as normas exigidas pelo Programa em Apadrinhamento Afetivo. A falta de documentação, a existência de um processo jurídico envolvendo crianças e adolescentes, a ausência nas oficinas, por exemplo, podem impedir a homologação final dos candidatos.

A análise dos dados obtidos nos documentos do Programa revelou que apenas 59 apadrinhamentos foram efetivados desde a primeira edição (ver Figura 1). Isso significa que dentre as 148 pessoas que se candidataram apenas $59(39,8 \%)$ cumpriram todas as exigências sendo habilitadas para madrinha/ padrinho. Esse resultado pode ser um tanto controverso. Se por um lado a seleção daqueles que se candidatam diminui a chance de atender a todas as meninas e os meninos que estão aptos a receber um padrinho ou madrinha, por outro aumenta a possibilidade de que essas relações sejam de cuidado. $\mathrm{O}$ processo de seleção dos candidatos a cuidadores parece ser essencial para garantir a proteção daqueles que já vivenciaram tantas situações de violação. O apadrinhamento afetivo deve possibilitar uma convivência harmoniosa e positiva para além do acolhimento, portanto a habilitação dos padrinhos e madrinhas é um passo importante para assegurar a criança e/ou o adolescente um espaço seguro e um adulto disponível afetivamente.

Ao analisar a situação atual dos 59 apadrinhamentos diferentes desfechos foram encontrados. Dentre os 59 casos identificados, 25 apadrinhamentos ainda estão ativos, dois evoluíram para a adoção, três estão sob análise judicial para a adoção (sendo que os padrinhos/ madrinhas possuem a guarda provisória dos afilhados), cinco houve rompimento de vínculos devido ao retorno do afilhado para a família de origem e nos outros 24 casos não havia informação suficiente para delimitar o que havia acontecido.

Daqueles 25 apadrinhamentos ativos, foi possível identificar que os 25 afilhados ainda se encontram nas instituições de acolhimento aguardando a possibilidade de inserção em famílias substitutas. O Programa Apadrinhamento Afetivo na tentativa de possibilitar o afeto na vida de daqueles que possuem remota chance de adoção está cumprindo seu papel. O contato com outras pessoas fora do contexto institucional pode ampliar as oportunidades e oferecer um tratamento individualizado que, na maioria das vezes, é impossível dentro do acolhimento.

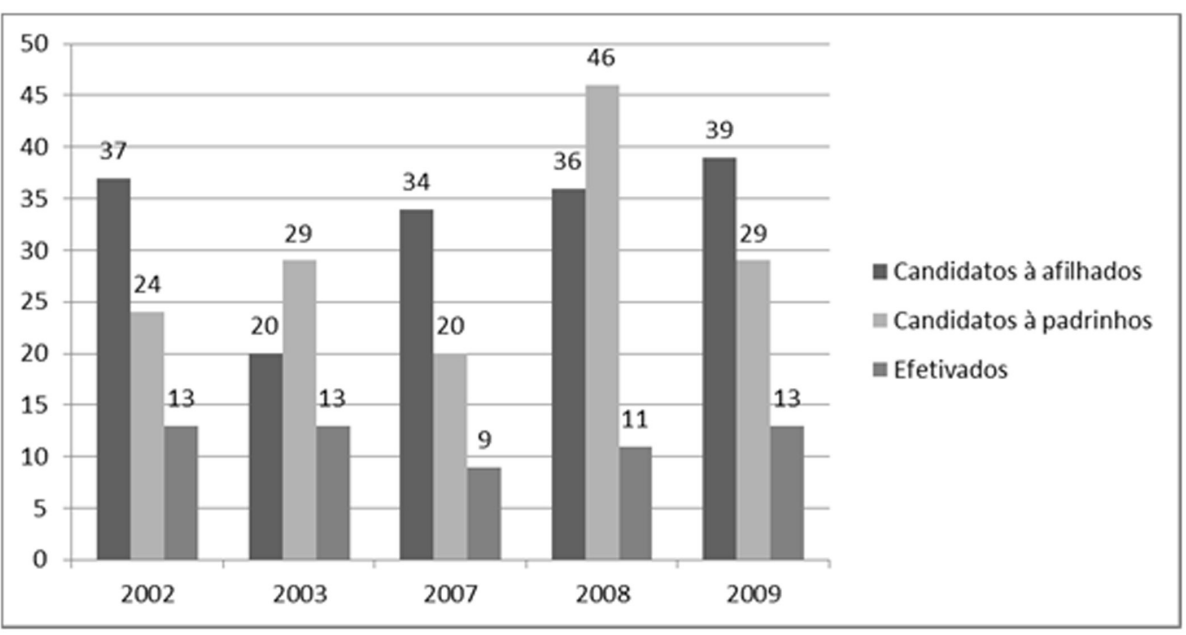

Figura 1. Evolução do Programa Apadrinhamento Afetivo ao longo de cinco edições. 
Os dados revelaram ainda que existem cinco afilhados morando com as madrinhas, sendo que destes dois casos são de adoção e três casos de guarda provisória. Embora o Programa não tenha como objetivo a adoção e não permita que pessoas que participam do Cadastro Nacional de Adoção sejam candidatas, é possível que a relação de afeto estabelecida através do apadrinhamento evolua para a adoção. Para tanto, os padrinhos e madrinhas devem buscar os caminhos legais para que a adoção aconteça. É importante que essa realidade seja discutida com os candidatos desde o momento das oficinas, já que o Programa do Apadrinhamento não pode ser um teste ou um treino para uma futura adoção. Essa questão precisa ser tratada antes da habilitação do candidato para evitar que falsas expectativas sejam fomentadas nos padrinhos e/ou madrinhas. Quando verificada essa intenção por parte do candidato é necessário que a equipe responsável pela avaliação e habilitação esclareça os objetivos do Programa Apadrinhamento e, quando necessário, encaminhe para a pessoa interessada em adotar para o Cadastro Nacional da Adoção.

Dias, Silva e Fonseca (2008) ao investigar as percepções e as vivências da adoção tardia realizada por quatro pais adotivos identificaram que o apadrinhamento foi sugerido como um caminho possível para o estabelecimento de vínculo de aproximação. Talvez o apadrinhamento referido no estudo citado não seja exatamente o mesmo proposto pelo Programa aqui investigado, entretanto, é preciso atenção para evitar a habilitação de pessoas que venham em busca desse objetivo.

O cumprimento das exigências relacionadas aos candidatos é fundamental para a garantia de uma relação saudável e favorável para a criança e o adolescente apadrinhado. Da mesma forma, é fundamental que os responsáveis pela execução do Programa cumpram os requisitos para a inserção daqueles que vivem nos acolhimentos institucionais para evitar qualquer outro problema. No entanto, a análise do Programa evidenciou o registro de cinco casos em que houve o retorno de crianças e adolescentes apadrinhados para a família de origem, demonstrando que não foi cumprido o seguinte critério - situação jurídica definida. Isso significa que foram inseridas crianças e adolescentes que ainda tinham alguma chance de voltar para as suas famílias. Aquelas famílias que não foram destituídas do poder familiar devem ter prioridade sobre os seus filhos e esses vínculos devem ser foco de atenção para que a reinserção familiar seja possível. Siqueira, Zoltowski, Giordani, Otero e Dell'Aglio (2010) salientam que é obrigação de todas as instituições de abrigo promover o convívio familiar e favorecer a reinserção quando acordada pelo judiciário. Esse dever também está descrito no artigo 92 de Estatuto da Criança e do Adolescente quando são enfatizados os princípios norteadores para o funcionamento dos acolhimentos institucionais. Portanto a relação com a família de origem deve ser privilegiada acima de qualquer outra possibilidade. A inclusão de uma criança e/ou um adolescente no Programa Apadrinhamento Afetivo que ainda tem chance de voltar para a sua família pode causar confusão e gerar conflitos para todos os envolvidos.

Por fim, os dados capturados nos documentos do Programa Apadrinhamento Afetivo não foram suficientes para identificar o desfecho dos outros 24 casos de apadrinhamentos efetivados. Muitos dados cadastrais estavam desatualizados (ex. endereço e telefone) e incompletos, fatos que impediram a identificação da situação atual desses 24 casos de apadrinhamento. A ausência dessas informações sugere a necessidade de um acompanhamento longitudinal dos casos, uma vez que é necessário atualizar o cadastro constantemente e avaliar a vinculação existente entre os cuidadores e seus afilhados. Na tentativa de compreender a efetividade dessas relações para além dos números encontrados, o presente estudo buscou realizar uma segunda etapa de coleta de dados. Partindo das informações coletadas no estudo documental buscou-se contatar as 25 crianças e adolescentes apadrinhadas que ainda se encontravam nos acolhimentos institucionais e seus respectivos padrinhos e madrinhas.

\section{Quem são os afilhados e o que pensam sobre o Programa Apadrinhamento Afetivo?}

$\mathrm{Na}$ segunda etapa do estudo, os 25 afilhados que se encontram no acolhimento institucional foram pessoalmente contatados. Uma entrevista semiestruturada foi proposta com o objetivo de conhecer o perfil dos afilhados e o significado atribuído por eles/ elas ao Programa Apadrinhamento Afetivo. Apenas dois meninos não aceitaram participar do estudo, sendo então realizadas 23 entrevistas no total.

Os dados sobre o perfil que contemplam a idade, sexo, o tempo de institucionalização e o motivo que levou a criança e/ou o adolescente para o acolhimento estão apresentados na Tabela 1 .

É possível verificar na Tabela 1 que as crianças e os adolescentes participantes do Programa Apadrinhamento Afetivo têm idades entre oito e 17 anos $(M=12,1 ; d p=1,8), 12$ são do sexo feminino e 11 do sexo masculino, sendo a maioria acolhida por negligência, maltrato e dependência química dos pais. O tempo de permanência no acolhimento institucional varia entre dois e 13 anos $(M=6,5 ; d p=3,06)$. 
TABELA 1

Perfil dos afilhados entrevistados

\begin{tabular}{|c|c|c|c|c|}
\hline$I D$ & Sexo & Idade & $\begin{array}{c}\text { Tempo acolhimento } \\
\text { (anos) }\end{array}$ & Motivo acolhimento \\
\hline 1 & Masculino & 13 & 8 & Negligência \\
\hline 2 & Masculino & 12 & 2 & Dependência química \\
\hline 3 & Masculino & 13 & 2 & Abandono \\
\hline 4 & Masculino & 11 & 5 & Negligência \\
\hline 5 & Masculino & 13 & 6 & Negligência/dependência química \\
\hline 6 & Masculino & 13 & 5 & Maus tratos/agressão \\
\hline 7 & Masculino & 8 & 5 & Maus tratos/agressão \\
\hline 8 & Masculino & 12 & 9 & Negligência \\
\hline 9 & Masculino & 12 & 10 & Maus tratos \\
\hline 10 & Masculino & 12 & 2 & Dependência química \\
\hline 11 & Masculino & 17 & 13 & Maus tratos/abandono \\
\hline 12 & Feminino & 14 & Sem informação & Sem informação \\
\hline 13 & Feminino & 9 & 2 & Dependência química \\
\hline 14 & Feminino & 12 & 6 & Negligência/dependência química \\
\hline 15 & Feminino & 11 & 9 & Mãe deficiente mental \\
\hline 16 & Feminino & 13 & 10 & Negligência \\
\hline 17 & Feminino & 14 & 10 & Negligência \\
\hline 18 & Feminino & 12 & 6 & Maus tratos/agressão fisica \\
\hline 19 & Feminino & 11 & 4 & Abuso sexual \\
\hline 20 & Feminino & 11 & 6 & Negligência/dependência química \\
\hline 21 & Feminino & 14 & 6 & Maus tratos \\
\hline 22 & Feminino & 12 & 9 & Mãe deficiente mental \\
\hline 23 & Feminino & 11 & 8 & Negligência \\
\hline
\end{tabular}

Esses dados iniciais sobre o perfil dos afilhados revelam que o Programa tem cumprido o seu papel ao priorizar a inserção daqueles que possuem chance remota de adoção devido à idade avançada e que já se encontram no acolhimento algum tempo. Weber (1996) já apontava que crianças com idade superior a três anos já eram consideradas "velhas" e não eram alvo dos pretendentes a adoção prejudicando a saída delas dos acolhimentos. Estudos mais recentes continuam confirmando que a idade ainda é um desafio para a garantia da convivência familiar (Costa e RossettiFerreira, 2007; Guareschi, Strenzel, Bennemann, 2007; Pereira e Costa, 2005). O Programa Apadrinhamento Afetivo na tentativa de possibilitar o afeto na vida daqueles que ainda não foram inseridos em famílias substitutas.

Interessante destacar ainda que foram privilegiados aqueles que estão acolhidos devido à negligência dos cuidadores, a presença de maus tratos e de dependência química dos pais. O Apadrinhamento é uma oportunidade para que essas crianças e adolescentes tenham contato com adultos que possam exercer de fato o cuidado. Talvez em suas histórias de vida a atenção, o carinho e o afeto não tenham sido prioridade, portanto o programa tem como objetivo propiciar vivências positivas e saudáveis. Oliveira e Próchno (2010) destacaram que aqueles que vivenciam o abrigo acabam por estabelecer relações afetivas com os cuidadores/monitores e relações de amizade com as outras crianças e adolescentes que ali estão, mas também desejam construir vínculos com pessoas que estão fora do contexto institucional. Essa expectativa pode ser nutrida e alcançada com a inserção da criança e do adolescente no Programa, especialmente quando o tempo de acolhimento é prolongado - como é o caso de alguns entrevistados.

Embora os objetivos estejam claros para aqueles que selecionam as crianças e os adolescentes que irão ser incluídos no Programa ainda não estão totalmente esclarecidos para os afilhados Essa resposta ficou evidenciada quando 10 entrevistados disseram não saber o que é o Programa Apadrinhamento Afetivo. Contudo, quando questionados sobre a existência do padrinho e da madrinha todos responderam de forma afirmativa. Esse resultado leva a crer que o nome técnico do Programa não é totalmente compreendido pelos próprios participantes, mas a presença dessas pessoas sim. 
Ao avaliar o significado atribuído a essas pessoas, diferentes respostas emergiram, mas puderam ser agrupadas em duas categorias. A primeira contemplou respostas que trataram do padrinho/madrinha como alternativa de cuidado fora do espaço institucional, como por exemplo, os relatos que seguem: "É bom ter padrinhos, porque antes eu ficava sozinho domingo aqui no acolhimento" (R., 13 anos) e "É que eu não preciso só ficar trancada aqui” (T., 11 anos).

A segunda categoria agrupou respostas que traziam o padrinho e a madrinha como figura de afeto. Relatos direcionados ao vínculo positivo estabelecido com o adulto foram bastante frequentes como, por exemplo:

"Gosto porque ela me leva para passear, às vezes a gente sai para brincar" (J., 12 anos). A possibilidade de construir vínculos parece ser fundamental para os entrevistados. Todos foram unânimes ao afirmar que a vida havia se tornado mais interessante e melhor após conhecer o padrinho e a madrinha, conforme o relato de L., 17 anos: "Ah, muita coisa mudou na minha vida... Eu aprendi a andar de ônibus sozinho, coisa que eu não sabia andar. Eu tinha medo de pegar o ônibus sozinho, de pegar o ônibus errado, e agora eu não tenho medo, passou o medo, eu tinha muita insegurança... meus padrinhos me deram muito mais coisa que eu não tinha....".

Interessante destacar que quando questionados sobre o que não gostavam nessa relação alguns entrevistados afirmaram que não gostavam das cobranças relacionadas à vida escolar (ex. fazer os temas, ter boas notas). Os demais depoimentos foram todos afirmando que não existia nada mais que não gostavam. Apesar das crianças relatarem esse fator das cobranças escolares, ele é visto como positivo, pois é um cuidado e atenção que eles acabam recebendo dos padrinhos, sendo que na instituição, devido ao elevado número de crianças, esse cuidado mais próximo e individual é dificultado. Os limites impostos pelos padrinhos também pode ser, sob a perspectiva do apadrinhado, um aspecto negativo, porém em muitos casos são os padrinhos que mostram como funciona uma dinâmica familiar na qual os limites são constituintes, pois em suas famílias, muitas vezes, esse limite era faltante.

Entretanto, o fator mais relevante relacionado ao apadrinhamento é o afeto que os padrinhos despendem para seus afilhados. Esse afeto se faz fundamental na vida dessas crianças, pois como citado acima por Oliveira e Próchno (2010) e Alexandre e Vieira (2004), a provação de relações de afeto acaba por interferir na construção de vínculos afetivos e na interação com o meio e com outros. As demonstrações do quanto esse afeto é positivo podem ser vistas na melhora escolar, na melhor interação da criança com seus pares e no carinho com o qual eles falam a respeito de seus padrinhos.

Para complementar o que foi verificado através das informações fornecidas pelos afilhados, foi investigado quem são esses padrinhos e o que pensam a respeito das questões relacionadas à participação no programa.

\section{Quem são os padrinhos e madrinhas e o que pensam sobre o Programa Apadrinhamento Afetivo?}

Nessa etapa do estudo, foram convidados todos os padrinhos e madrinhas das 23 crianças e adolescentes entrevistados. Aceitaram participar do estudo 18 pessoas, sendo 15 madrinhas e três padrinhos. A maior parte é casada $(55,5 \%)$, possui filhos biológicos $(88,8 \%)$ e tem idades entre 30 e 60 anos $(M=49,11$; $d p=8,27)$.

O desejo de ajudar outras pessoas foi citado como motivador para a entrada no Programa Apadrinhamento Afetivo por 14 entrevistados. A inserção dessas pessoas no Programa aconteceu em diferentes momentos: três participam desde a edição de 2002, um desde 2003, sete desde 2007 e sete desde 2008. Dentre os 18 entrevistados, 15 afirmaram ter um afilhado afetivo, três disseram ter dois afilhados e um possui três, totalizando 24 crianças e adolescentes beneficiados diretamente. $\mathrm{O}$ tempo de contato entre os padrinhos/madrinhas e seus afilhados variou entre 2 meses e 10 anos, revelando que alguns tinham contato com a criança e/ou o adolescente mesmo antes de participar do Programa.

Ao questionar a frequência do encontro, a maioria afirmou conviver pelo menos uma vez por semana com seu afilhado, sendo que todos buscam as crianças e adolescentes nos períodos de festas (Natal, Ano Novo). O Programa possibilita assim a chance de compartilhar experiências e momentos de felicidade em família. Para alguns esses momentos podem ser estendidos, nesse estudo essa situação é vivenciada por nove afilhados que são levados para passar as férias escolares na residência de seu cuidador.

A relação com o afilhado foi avaliada de forma positiva por todos os entrevistados. Contudo, alguns afirmaram já ter vivenciado alguma dificuldade ao longo do processo, especialmente, no que se refere à agressividade do afilhado, ao difícil relacionamento do afilhado com os filhos da madrinha e do padrinho, ao relacionamento conturbado com o acolhimento institucional e ao preconceito demonstrado pelas pessoas que convivem com a família do padrinho e da madrinha. As dificuldades relacionadas ao comportamento dos afilhados podem ser interpretadas como uma forma que estes encontram para se proteger. É característica do contexto no qual estão inseridos 
relações instáveis, podendo, por isso, a agressividade ser vista como uma forma de dificultar uma aproximação, visando o não sofrimento com possíveis rompimentos. Essa agressividade também pode servir como um teste por parte do afilhado para avaliar a persistência na manutenção da relação. As crianças que vivem em instituições ainda possuem estigmas, sendo muitas vezes vistos como incapazes de um desenvolvimento saudável, ou ligadas a comportamentos infratores, sendo este fator não comprovado pela realidade. A relação com o acolhimento se torna conturbada quando as crianças são impedidas de sair nos finais de semana, devido a punições sofridas por mau comportamento, ou ainda, quando há uma pressão provenientes dos diretores da organização com relação à adoção dos afilhados pelos padrinhos.

Ao perguntar se haveria interesse na adoção do afilhado, oito disseram já ter pensado sobre o assunto e ter vontade de assumir essa tarefa, enquanto dez relataram que não. Relatos como "Não temos interesse na adoção, mas ela (afilhada) tem todo nosso apoio quando sair da instituição dentro das nossas possibilidades" e "Não, porque tenho uma vida muito atribulada, trabalho muito, três turnos por dia. Não teria como orientá-las e protegê-las de maneira adequada" evidenciam que o apadrinhamento pode ser uma alternativa de apoio psicológico e afeto fora do acolhimento institucional. Os padrinhos e madrinhas acabam por se tornar figuras de referência que oferecem cuidado e orientação ampliando as perspectivas de futuro dos jovens afilhados.

\section{CONSIDERAÇÕES FINAIS}

A análise dos dados permite concluir que o Programa Apadrinhamento Afetivo está cumprindo com seu objetivo ao possibilitar às crianças/adolescentes que se encontram em acolhimentos institucionais à convivência familiar e comunitária através do contato com os padrinhos/madrinhas. Ao longo de cinco edições o Programa tem permitido que adultos assumam um papel de cuidador na vida daqueles que nem sempre receberam o afeto que mereciam e estabeleceram vínculos duradouros e significativos. Entretanto, é importante refletir sobre a flexibilidade dos critérios de inserção. O descumprimento de algum critério pode fragilizar a relação ou até mesmo prejudicar a construção de vínculos, especialmente, quando são incluídos aqueles que ainda possuem qualquer chance de retornar para a sua família de origem.

O Programa Apadrinhamento Afetivo deve propiciar uma nova oportunidade de vida para aqueles que acabam crescendo dentro dos contextos insti- tucionais. Embora o caráter temporário seja identificado no Estatuto da Criança e do Adolescente e reiterado Lei 12.010 que altera o art.19, no $\S 2^{\circ}$ da Lei $n^{\circ} 8.069$, a qual prevê que a permanência em um acolhimento não deve ser superior a dois anos, é sabido que quando existe destituição do poder familiar o interesse superior dessa é ser inserida em uma família substituta. No entanto, não existem muitas famílias substitutas interessadas na adoção de crianças com idades superior a oito anos. O Conselho Nacional de Justiça (CNJ), através do Cadastro Nacional de Adoção (CNA), em um levantamento realizado em novembro de 2011, verificou que cerca de $59 \%$ dos cadastrados para adoção querem adotar crianças de até 3 anos de idade.

Portanto, é preciso que exista uma maior divulgação e um maior investimento em programas que fomentem o cuidado e a convivência familiar e comunitária, como o Apadrinhamento Afetivo. É de extrema importância o papel dos cuidadores na vida daqueles que já vivenciaram tantas perdas e violações. A possibilidade de conhecer novas relações familiares baseadas no afeto tem um custo muito baixo, mas um alto impacto e um grande poder de transformação.

A escuta das crianças e adolescentes afilhados permitiu conhecer os aspectos positivos dessas novas relações. As vivências compartilhadas corroboram as reflexões trazidas pela literatura. Mota e Matos (2008) já afirmavam que o contato com as pessoas que estão fora do contexto institucional permite uma organização emocional e afetiva que acaba por fortalecer os fatores de proteção da pessoa, oferecendo maior consistência interna e segurança nas relações humanas. Isso significa que ao entrar em contato com o padrinho e com a madrinha, o afilhado não só amplia a sua rede de relações, como fortalece a sua capacidade de estabelecer novos vínculos de afeto. Nessa mesma direção, Barros e Fiamenghi Jr (2007) sugerem que quanto maior o afeto recebido, maior a chance de a criança tornar-se um adulto moral e socialmente independente. Dessa forma, a reestruturação dos conceitos familiares e afetivos, propiciados com o contato entre padrinhos e apadrinhados, agrega e fortalece a confiança, a esperança e o fortalecimento nas relações familiares. $\mathrm{O}$ convívio com a rede de relações dos padrinhos permite aos apadrinhados, oportunidades de enriquecimento social, cultural e a definição de um exemplo e/ou modelo de convívio e práticas familiares. O exercício das frustrações, conquistas e emoções relacionadas ao convívio com um núcleo familiar, define e reafirma as práticas afetivas que contribuem com a formação da moral e social dos apadrinhados.

Outra importante contribuição é a oportunidade oferecida aos adolescentes no momento em que 
completam 18 anos e necessitam sair da instituição de acolhimento. Nesse momento, o padrinho e a madrinha assumem um importante papel afetivo e de suporte emocional. A certeza de ter uma pessoa fora do contexto institucional facilita essa transição e ameniza a sensação de solidão.

Portanto, o Programa Apadrinhamento Afetivo é uma alternativa de cuidado e de proteção efetiva para aqueles que não têm mais chance de ser reinserido na sua família de origem e para aqueles que têm remota chance de adoção.

\section{REFERÊNCIAS}

Alexandre, D. T., \& Vieira, M. L. (2004). Relação de apego entre crianças institucionalizadas que vivem em situação de abrigo. Psicologia em Estudo, 9(2), 207-217.

Barros, R. C., \& Fiamenghi Jr., G. A. (2007). Interações afetivas de crianças abrigadas: um estudo etnográfico. Ciência \& Saúde Coletiva, 12(5), 1267-1276.

Brasil (1990). Estatuto da criança e do adolescente. Diário Oficial da União. Lei n. 8069, de 13 de julho de 1990. Brasília, DF.

Cavalcante, L. I. C., Magalhães, C. M. C., \& Pontes, F. A. R. (2007). Institucionalização precoce e prolongada de crianças: discutindo aspectos decisivos para o desenvolvimento. Aletheia, 25, 20-34.

Conselho Nacional de Justiça. (2011). Cor e idade ainda são entraves à adoção. Recuperado em 13 novembro, 2011 de http://www.adocaobrasil.com.br/2011/11/cor-e-idade-ainda-saoentraves-adocao.html

Costa, N. R. A., \& Rossetti-Ferreira, M. C. (2007). Tornar-se pai e mãe em um processo de adoção tardia. Psicologia Reflexão e Crítica, 20(3), 425-434.

Costa, N. R. A., \& Rossetti-Ferreira, M. C. (2009). Acolhimento familiar: uma alternativa de proteção para crianças e adolescentes. Psicologia Reflexão e Crítica, 22(1), 111-118.

Dias, C., Silva, R. \& Fonseca, C. (2008). A adoção de crianças maiores na perspectiva dos pais adotivos, Contextos Clínicos, $1(1), 28-35$.

Guareschi, N. M. F., Strenzel, J. C., \& Bennemann, T. (2007). Quem está apto?: A prática da adoção e marcadores identitários. Aletheia, 25(1), 163-176.

Instituto Amigo De Lucas. (2004). Programa de Apadrinhamento Afetivo - Rio Grande do Sul. Consultado em 1 maio, 2011 de http://www.amigosdelucas.org.br

Instituto de Pesquisa Econômica Aplicada. (2003). Levantamento Nacional dos Abrigos para Crianças e Adolescentes da Rede de Serviço de Ação Continuada (SAC) (Relatório de Pesquisa $\mathrm{n}^{\circ} 1$ ). Brasília, DF: Autor.

Lei 12.010 de 29 de julho de 2009 (2009). Dispõe sobre adoção. Brasília, DF. Consultado em 26 outubro, 2011, de http://www.planalto. gov.br/ccivil_03/_Ato2007-2010/2009/Lei/L12010.htm

Ministério do Desenvolvimento Social e Combate à Fome. Secretaria Especial de Direitos Humanos. (2006). Plano nacional de promoção, defesa e garantia do direito de crianças e adolescentes à convivência familiar e comunitária. Brasília, DF: Autores.

Moré, C. L. O. O., \& Sperancetta, A. (2010). Práticas de pais sociais em instituições de acolhimento de crianças e adolescentes. Psicologia \& Sociedade, 22(3), 519-528.

Mota, C. P., \& Matos, P. M. (2008). Adolescência e institucionalização numa perspectiva de vinculação. Psicologia \& Sociedade, 20(3), 367-377.
Noal, J., \& Neiva-Silva, L. (2007). Adoção, adoção tardia e apadrinhamento afetivo: intervenção em relação a crianças e adolescentes vítimas de abandono e institucionalizadas. In Hutz, C. (Org). Prevenção e intervenção em situações de risco e vulnerabilidade (pp. 04-48). São Paulo: Casa do Psicólogo.

Oliveira, A. P. G., \& Milnitsky-Sapiro, C. (2007). Políticas públicas para adolescentes em vulnerabilidade social: abrigo e provisoriedade. Psicologia Ciência e Profissão, 27(4), 622-635.

Oliveira, S. V., \& Próchno, C. C. S. C. (2010). A vinculação afetiva para crianças institucionalizadas à espera de adoção. Psicologia Ciência e Profissão, 30(1), 62-84.

Padilha, M., Borba, R., Grillo, F., Dahmer, C., \& Paludo, S. (2010). Apadrinhamento afetivo: uma alternativa de cuidado às crianças institucionalizadas, Revista do SAJU: para uma visão crítica e interdisciplinar do Direito, 6(1), 79-104.

Pereira, J., \& Costa, L. (2005). Os desafios na garantia do direito à convivência familiar. Rev Bras Cresc Desenv Hum, 15(1), 19-31.

Silva, E. R. (2004). O direito à convivência familiar e comunitária: Os abrigos para crianças e adolescentes no Brasil. Brasília: IPEA/CONANDA.

Silva, E. R. A., \& Aquino, L. M. C. (2005). Os abrigos para crianças e adolescentes e o direito à convivência familiar e comunitária Políticas sociais - acompanhamento e análise, 11, 186-193. Instituto de Pesquisa Econômica Aplicada.

Siqueira, A. C., Betts, M. K., \& Dell'Aglio, D. D. (2006). A rede de apoio social e afetivo de adolescentes institucionalizados no sul do Brasil. Revista Interamericana de Psicologia, 40(2), 149-158.

Siqueira, A. C., \& Dell'Aglio, D. D. (2006). O impacto da institucionalização na infância e na adolescência: uma revisão de literatura. Psicologia \& Sociedade, 18(1), 71-80.

Siqueira, A.C., Tubino, C. L., Schwarz, C., \& Dell'Aglio, D. D. (2009). Percepção das figuras parentais na rede de apoio de crianças e adolescentes institucionalizados. Arquivos Brasileiros de Psicologia, 61(1). Recuperado em 12 de novembro 2011 , de http://146.164.3.26/seer/lab19/ojs2/index.php/ojs2/article/ viewArticle/175/311.

Siqueira, A. C., Zoltowski, A. P., Giordani, J. P., Otero, T. M., \& Dell'Aglio. (2010). Processo de reinserção familiar: estudo de casos de adolescentes que viveram em instituição de abrigo. Estudos de Psicologia, 15(1), 07-15.

Sousa, K. K., \& Paravidini, J. L. L. (2011). Vínculos entre crianças em situação de acolhimento institucional e visitantes da instituição. Psicologia: Ciência e Profissão, 31(3), 536-553.

Souza, I. F., Cabral, J., \& Berti, R. B. (2010). O reconhecimento do direito da criança e do adolescente à convivência familiar e comunitária no Brasil. Espaço Jurídico (Joaçaba), 11(1), 125-148.

Vasconcelos, Q. A., Yunes, M. A.M., \& Garcia, N. M. (2009). Um estudo ecológico sobre as interações da família com o abrigo. Paidéia, 19(43), 221-229.

Weber, L. N. D., \& Kossobudzki, L. H. M. (1996). Filhos da solidão: institucionalização, abandono e adoção. Curitiba: Governo do Estado do Paraná.

Autores:

Juliana Sonego Goulart - Graduada em Psicologia pela Universidade Federal do Rio Grande.

Simone dos Santos Paludo - Doutorado em Programa de Pós-Graduação em Psicologia pela Universidade Federal do Rio Grande do Sul, Brasil. Professora Adjunto da Universidade Federal do Rio Grande, Brasil.

Endereço para correspondência:

Juliana Sonego Goulart

Rua Dona Lúcia, 33 apto 303 - Petrópolis

90000-000 Porto Alegre, RS, Brasil

E-mail: jusonego@gmail.com

Recebido em: 23.10 .2012

Aceito em: 10.10.2013. 